\title{
DHL Courier Service as an E-Courier Service: As Perspective of Pakistan
}

\author{
Javed Ramzan ${ }^{1} \quad$ Asif Siddique ${ }^{1} \quad$ Muhammad Naeem $^{1} \quad$ Muhammad Ikram Ullah $^{2} \quad$ Muhammad Umar $^{2}$ \\ Junaid Ghaffar $^{3} \quad$ Muhammad Aslam $^{3}$ saifullah Burero ${ }^{2}$ \\ 1. Department Of Computer Science, Bahauddin Zakariya University Sub Campus D.G.Khan, Pakistan \\ 2.Department Of Computer Science, KFUEIT, Rahim Yar Khan, Pakistan \\ 3.Department of Computer Science \& IT, Ghazi University, Dera Ghazi Khan, Pakistan
}

\begin{abstract}
It is a new global website; customers can order to send their documents, parcels and shipment from one place to another place. First Customers create account then transfer documents, parcels and shipments. Customer can check status with tracing number and receive updates in their email or mobile phone. Customers can also see detail about services and office time. On admin side managers should be added new branches and new employee. Admin can store consignment record and transfer it to the destination place. Admin should be updated consignment record which is delivered or not. PHP is the latest language for developing web applications. MySQL is used as backend. The main reason to use SQL Server was to make the data secure and also it provides greater compatibility with PHP language. The server I have used is XAMP Server. The beneficiaries of this research are the courier companies and related customers.
\end{abstract}

Keywords: E-courier Services, Customers, Destination Locator, Shipment Search

DOI: $10.7176 / \mathrm{CEIS} / 10-7-01$

Publication date: November 30th 2019

\section{Introduction}

This project is for online courier services system. Courier services are an important role in the world to transfer things one place to another place in today. I have selected to work on this project for sake of online this system. The basic theme is that the work which is currently being done manually in this organization to be now done with the help of computer [1]. This will bring efficiency in the system and also better facilitate the users send their documents or other shipment details online to the destination. In this organization, there may be many systems at work. The scope of our project is limited to the courier system[2]. The scope of my project is to add new employee, manager, calculation of freight of shipment from source to destination place. The objective of the project is to online the current manual system of the courier[3]. This includes activities. First authentication of login to use admin site. To facilitate add/update employees data[4]. To facilitate customer track its consignment online and check status. To facilitate admin updated status of consignment [5]. Tracing consignment result on provide short message on mobile and also on email.

\subsection{Feasibility Study}

An analysis and evaluation of a proposed project to determine if it is technically feasible, is feasible within the estimated cost, and will be profitable. Feasibility studies are almost always conducted where large sums are at stake. Also called feasibility analysis.[6]

\subsection{Existing System Data Gathering}

A key part of system analysis of the existing system is gathered in gall relevant information about the present system. The system analyst has to find out how the current system works [7]. He must know what information together, where to find it. How to collect it so he has to spend a lot of time in talking with users and gathering the information [8]. The various tools can also be used for gathering the information.

\subsubsection{What kinds of information do we need?}

Much of the information, we need to analyze is related to the organization, the user staff and the work flow as shown in figure below.

It depends, which type of information we need then we will proceed further to collect that information [9].

\subsubsection{Information sources: the major sources of information are:}

- User/Users staff of the system.

- Forms documents, manuals, reports etc. Used in the organization.

- Financial reports

- Personnel staff

- Computer programs of existing systems.

- Government documents, vendors, newspapers, journals 
- Procedure manuals and rule books which specify how various tasks are carried out in the Organization.

- Professional staff.

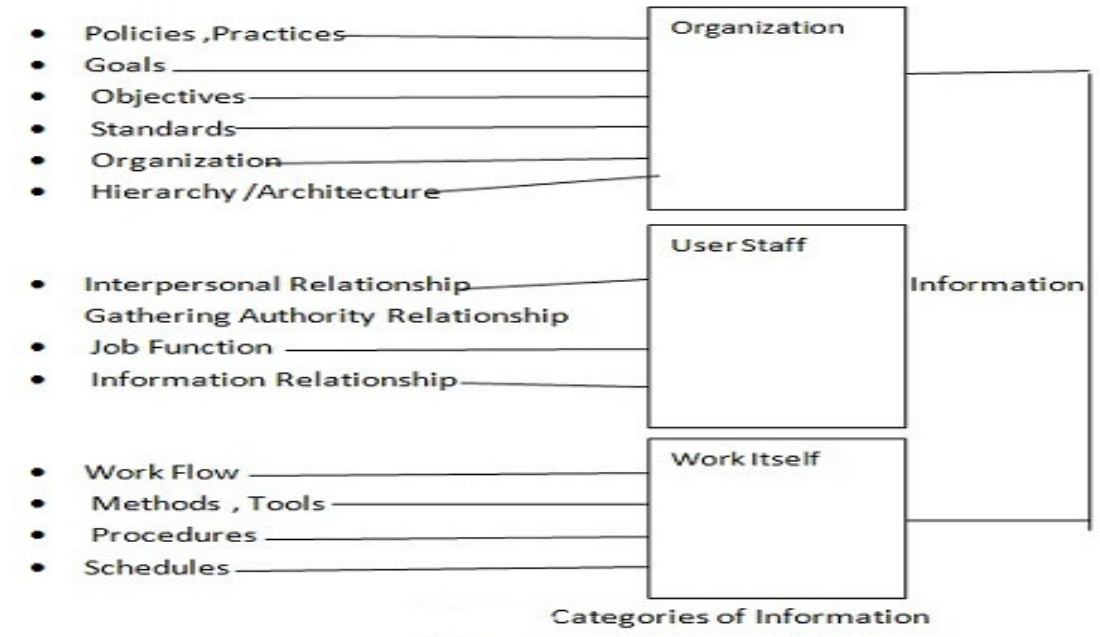

Fig1. Information

Information should be obtained from all the above mentioned sources. The consistency should be checked between them and summarized briefly [10].

1.2.3 How to collect the information: At this stage, the system analyst should decide which information method or tool should be used to collect the information and how it must be used. An important strategy to collect the information is that information and how it be acquired, accurately, methodically, under the right conditions and with minimum interruption to the user [11].

The various tools or methods are forms, procedures, on site observation, interviews and questionnaires etc. The information gathering methods are shown in figure below [12].

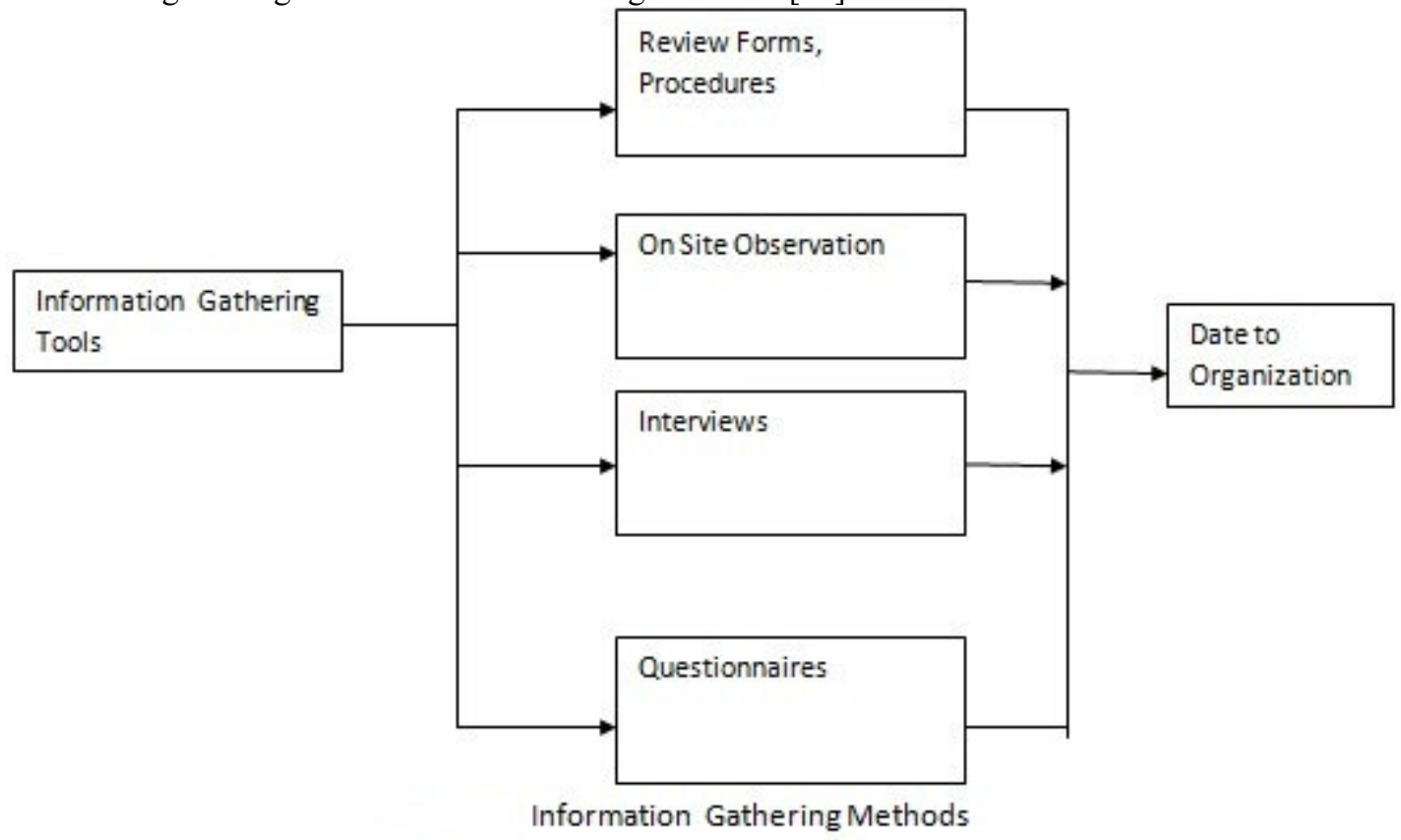

Fig. 2 Information types

\section{Existing System Data Analysis}

- Detail study of Existing system

It is very important for the designer to understand the existing system before its improvement. In this process the designer must know what he want to do [13].

- Understanding the Existing System

Without the proper understanding of the existing system the computerized system cannot work properly. The existing system of the DHL Courier system based on the manual system keep the record of the Add shipment, update, and delivered it[14]. 
- Add Shipment

In add shipment admin add post with sender and receiver information to transfer it.

- Update Shipment

The admin update shipment that the post where place. Using this portion when customer take update its consignment so he is known about it.

- Delivered Shipment

Admin use this portion to deliver the post that show it into the report when customer check status about his consignment then show that consignment is delivered.

\subsection{Requirements}

We analyzed our gathered information and we have decided our system should have following functionalities:

\section{Authentication of User}

- Admin

- Creation of Register User account

- Creation of Employee account

- Creation of Client account

- Authorization of admin

- Authorization of Client

- Authorization of Employee account

Functionality portion

- Admin

- Employee

- Visitor

- Client

- Register user

Different type of Module

- User related data entries

- Detailed Courier Tracking

- Summarized Courier Tracking

\section{Introduction to System Design}

This unit introduces students to requirements systems design, as well as databases. The principles and concepts of data storage, management and modeling are considered, including the role of data in business. The systems analysis and design component uses the traditional Structured Systems Analysis and Design Method (SSADM), and acts as a design precursor to the database section of the unit. Different methodologies for database design and implementation are covered. These include the flat file, hierarchical, network and relational approaches.

\subsection{Proposal System and its features}

A Systems Proposal is usually offered as both a written report and as a presentation. It often ends the second phase of a project, and suggests the following phases, most accurately the Design phase which should finally define the total project's costs, which are still very tentative. Its purpose is to convince the client's decision makers to proceed with the project, and to gain their consensus about the best way to proceed. Note that a Proposal is not a quotation! That comes later, when the specifications have been agreed. Its most important quality is credibility. These should be as specific as possible, and obviously attractive to the readers, individually and together.

\subsection{System Design using UML}

Unified Modeling Language is a graphical visualization language. It consists of a series of symbols and connectors that can be used to create process diagrams and is often used to model computer programs and workflows.

The UML standard defines nine types of diagram:

- Activity: model the flow of a system from action to response

- Class: define the structure of a system

- Collaboration: represents interaction between objects as a series of messages

- Component: describe the organization of software components

- Deployment: depict the physical resources of a system

- Object: describe the static structure of a system at a particular time

- Package: method of organizing the elements of a system into related groups

- Use Case: models the functionality of a system in terms of user interaction

- Sequence: describes the interaction between classes in terms of message exchange 
- State chart: describe the dynamic behavior of a system in response to external Stimulus

\subsection{Use Case Diagram}

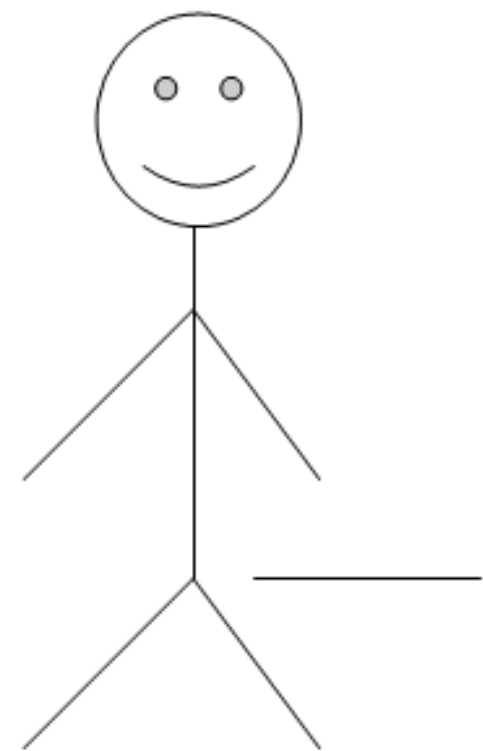

Admin

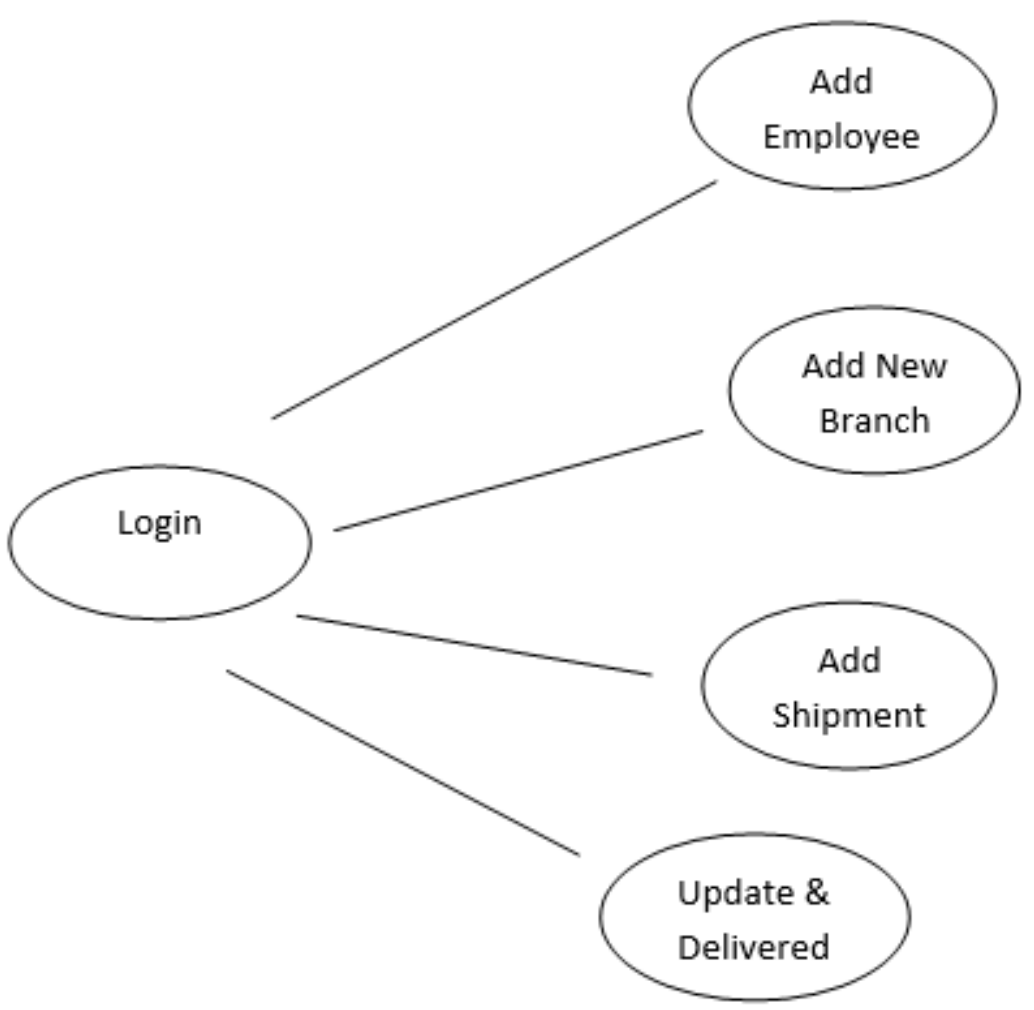

Fig. 3 Case diagram

\subsection{Sequence Diagrams}
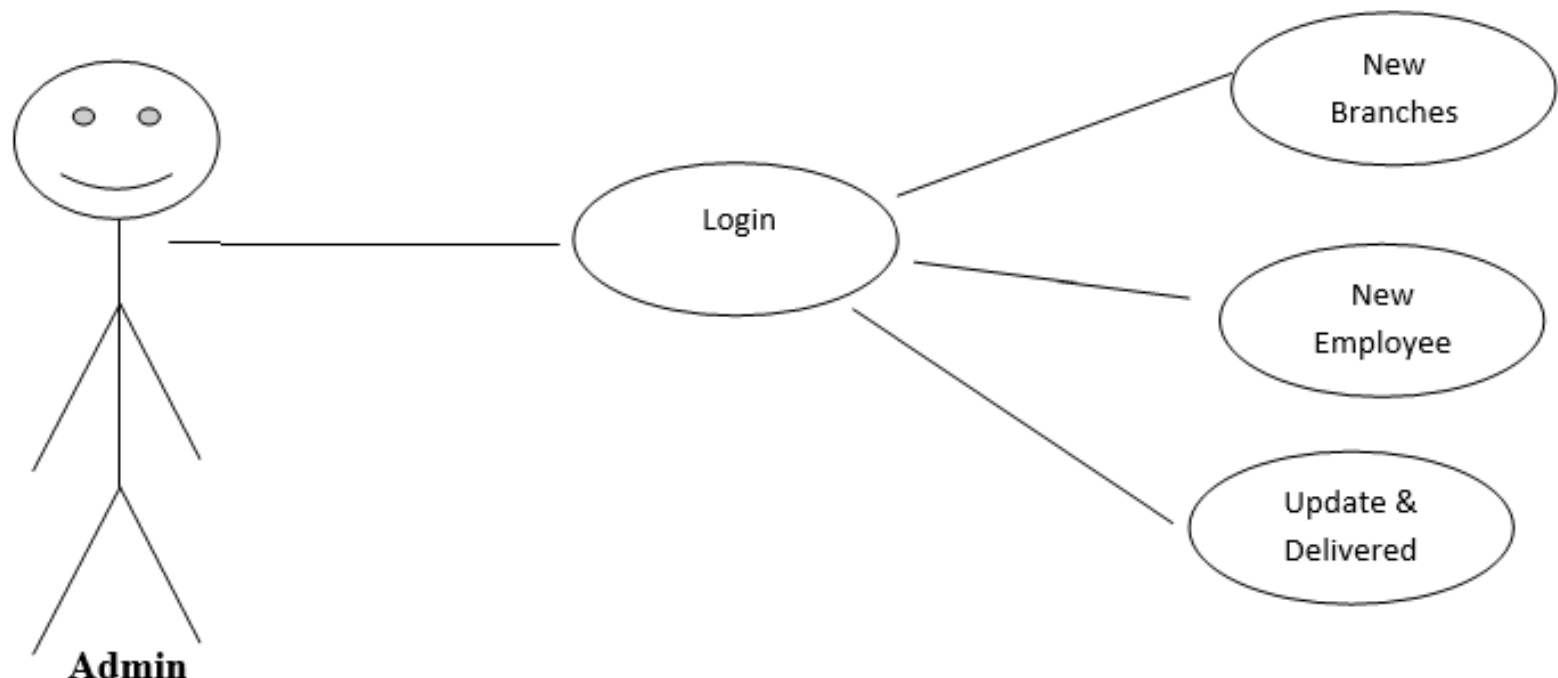

Fig 4. Sequence diagram

\section{Data Base Design}

A database is a place to store information. That information could be sales figures, an inventory of computers you own, a list of key customers, timesheet information; the possibilities are endless. By having the database on your site, you can easily share the information with people who need access to it.

\subsection{Entity}

The thing about which data is collected is called entity. For example Person, Place, Event etc. are entities. Entity 
is always written in rectangular box:

\subsection{Attribute}

Attributes define the properties of a data object and take on one of three different characteristics. They can be used to:

- Name an instance of data object.

- Describe the instance.

- Make reference to another instance in other table

$\bullet$

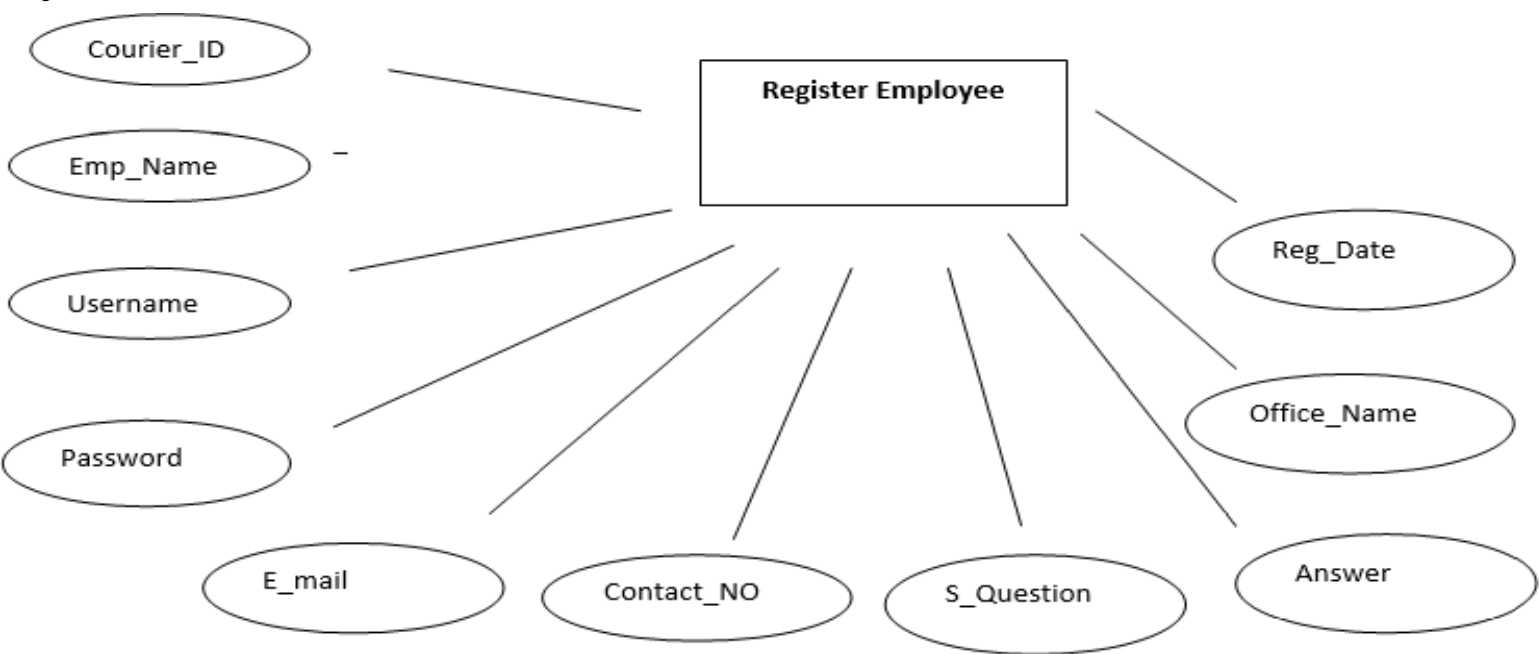

Fig 5. Attributes

\subsection{Data object}

A data object encapsulates data only there is no reference within a data object to operations that act on the data.

\subsection{ER Diagram of DHL Courier Management System}

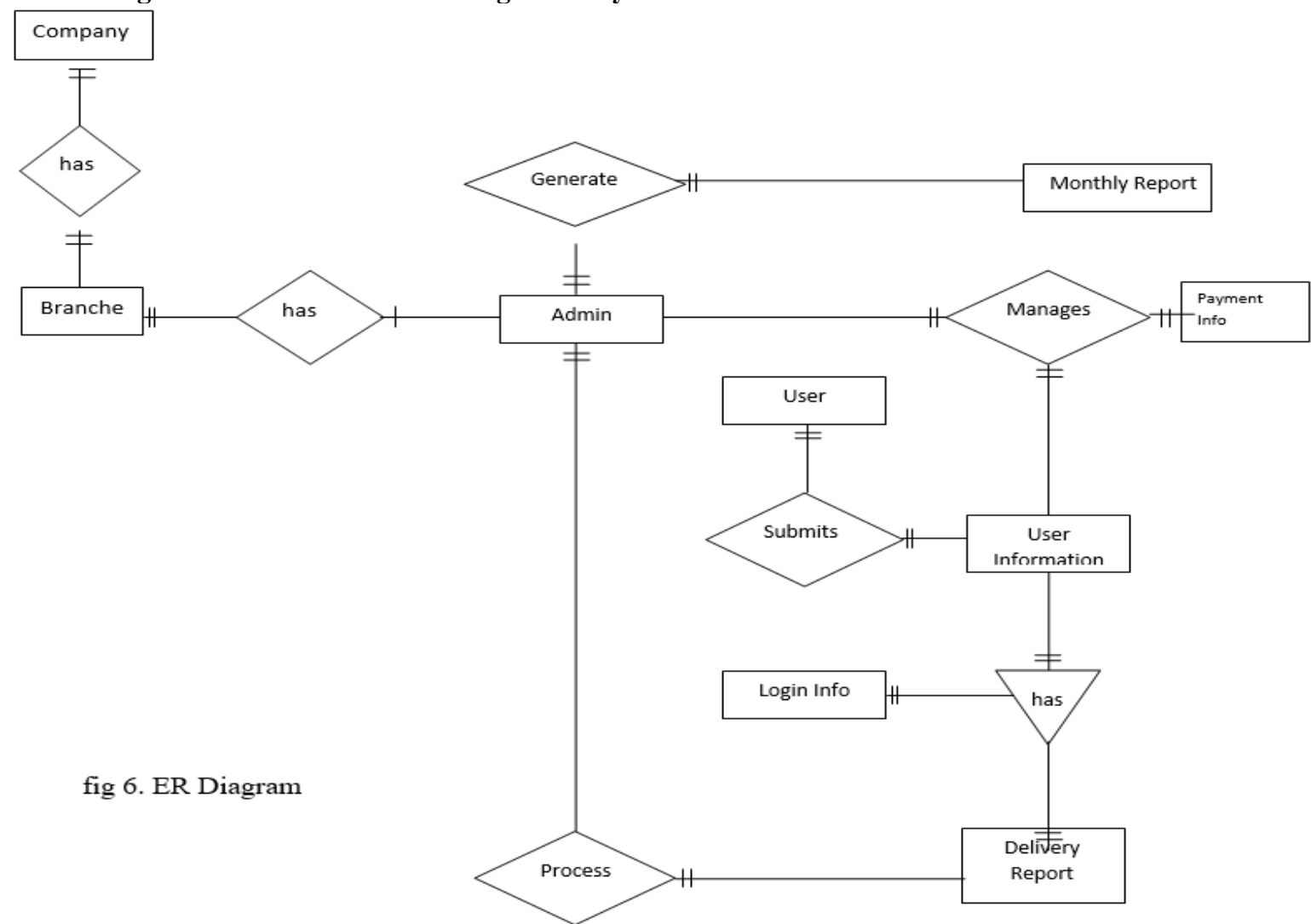




\subsection{Add Shipment}

\section{Table No.1 Add Shipment}

\begin{tabular}{|c|c|c|c|c|c|c|c|c|c|}
\hline 回 & 1 & $\underline{\text { Courier_ID }}$ & $\operatorname{int}(11)$ & & No & None & AUTO_INCREMENT & Change Drop Browse distinct values Primary & $\boldsymbol{\nabla}$ More \\
\hline$\square$ & 2 & Consign_NO & text & latin1_swedish_ci & No & None & & Change Drop Browse distinct values Primary & $\boldsymbol{\nabla}$ More \\
\hline$\square$ & 3 & Shiper_name & text & latin1_swedish_ci & No & None & & Change Drop Browse distinct values Primary & $\boldsymbol{\nabla}$ More \\
\hline$\square$ & 4 & Shiper_Phone & text & latin1_swedish_ci & No & None & & Change Drop Browse distinct values Primary & $\boldsymbol{\nabla}$ More \\
\hline 回 & 5 & Shiper_Addr & text & latin1_swedish_ci & No & None & & Change Drop Browse distinct values Primary & $\boldsymbol{\nabla}$ More \\
\hline 回 & 6 & Rcvr_Name & text & latin1_swedish_ci & No & None & & Change Drop Browse distinct values Primary & $\boldsymbol{\nabla}$ More \\
\hline$\square$ & 7 & Rcvr_Phone & text & latin1_swedish_ci & No & None & & Change $\odot$ Drop Browse distinct values Primary & $\boldsymbol{\nabla}$ More \\
\hline 口 & 8 & Rcvr_Addr & text & latin1_swedish_ci & No & None & & Change Drop Browse distinct values Primary & $\boldsymbol{\nabla}$ More \\
\hline 回 & 9 & Consig_Type & text & latin1_swedish_ci & No & None & & Change Drop Browse distinct values Primary & $\boldsymbol{\nabla}$ More \\
\hline$\square$ & 10 & weight & $\operatorname{int}(11)$ & & No & None & & Change Drop Browse distinct values Primary & $\boldsymbol{\nabla}$ More \\
\hline 回 & 11 & Invoice_NO & $\operatorname{int}(11)$ & & No & None & & Change Drop Browse distinct values Primary & $\boldsymbol{\nabla}$ More \\
\hline$\square$ & 12 & Qty & $\operatorname{int}(11)$ & & No & None & & Change Drop Browse distinct values Primary & $\boldsymbol{\nabla}$ More \\
\hline 回 & 13 & Book_mode & text & latin1_swedish_ci & No & None & & Change Drop Browse distinct values Primary & $\boldsymbol{\nabla}$ More \\
\hline$\square$ & 14 & Freight & $\operatorname{int}(11)$ & & No & None & & Change Drop Browse distinct values Primary & $\boldsymbol{\nabla}$ More \\
\hline 回 & 15 & Ship_Mode & text & latin1_swedish_ci & No & None & & Change Drop Browse distinct values Primary & $\boldsymbol{\nabla}$ More \\
\hline$\square$ & 16 & Pick_date & date & & No & None & & Change Drop Browse distinct values Primary & $\boldsymbol{\nabla}$ More \\
\hline$\square$ & 17 & Pick_time & time & & No & None & & Change Drop 10 Browse distinct values Primary & $\boldsymbol{\nabla}$ More \\
\hline$\square$ & 18 & Status & text & latin1_swedish_ci & No & None & & Change Drop Browse distinct values Primary & $\nabla$ More \\
\hline 回 & 19 & Comments & text & latin1_swedish_ci & No & None & & Change Drop Browse distinct values Primary & $\boldsymbol{\nabla}$ More \\
\hline 同 & 20 & Book Date & date & & No & None & & 9 Chance A Dron Rrowse distinct values Primarv & More \\
\hline
\end{tabular}

\subsection{Courier track}

Table No 3 Courier Track

\begin{tabular}{|c|c|c|c|c|c|c|c|}
\hline$=$ & & - & & $=$ & $=$ & -1 & \\
\hline \# Name & Type & Collation & Attributes & Null & Default & Extra & Action \\
\hline$\square 1 \underline{\mathbb{D}}$ & $\operatorname{int}(11)$ & & & No & None & AUTO_INCREMENT & 2 Change $D$ Drop Browse distinct values Primary $\boldsymbol{\nabla}$ More \\
\hline प 2 Courier_ID & $\operatorname{int}(11)$ & & & No & None & & $\rho$ Change $\odot$ Drop Browse distinct values Primary $\mathbf{\nabla}$ More \\
\hline 3 Consign_NO & text & latin1_swedish_i & & No & None & & $D$ Change $\odot$ Drop Browse distinct values Primary $\mathbf{\nabla}$ More \\
\hline (1) Current_City & text & latin1_swedish_ci & & No & None & & 2 Change $\odot$ Drop Browse distinct values Primary $\boldsymbol{\nabla}$ More \\
\hline 5 Status & text & latin1_swedish_i & & No & None & & Change $\odot$ Drop Browse distinct values Primary $\boldsymbol{\nabla}$ More \\
\hline$\square 6$ Comments & text & latin1_swedish_ci & & No & None & & 2 Change $\odot$ Drop Browse distinct values Primary $\mathbf{\nabla}$ More \\
\hline 7 Book_Time & datetime & & & No & None & & 2 Change 2 Drop 1 Browse distinct values Primary $\mathbf{\nabla}$ More \\
\hline
\end{tabular}

\subsection{New Officer Add}

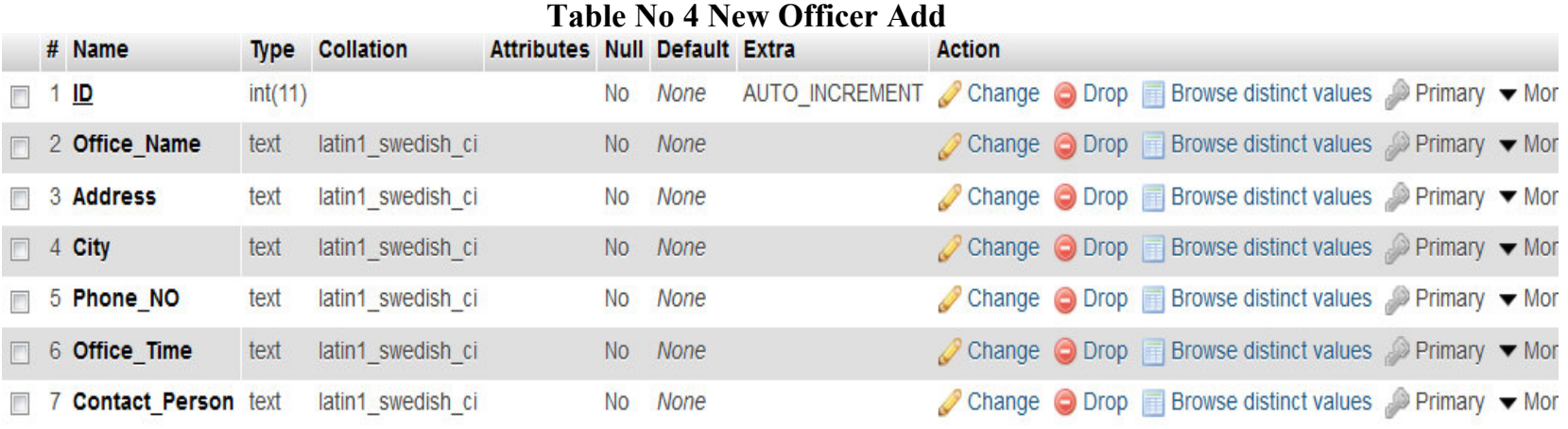




\subsection{New Office}

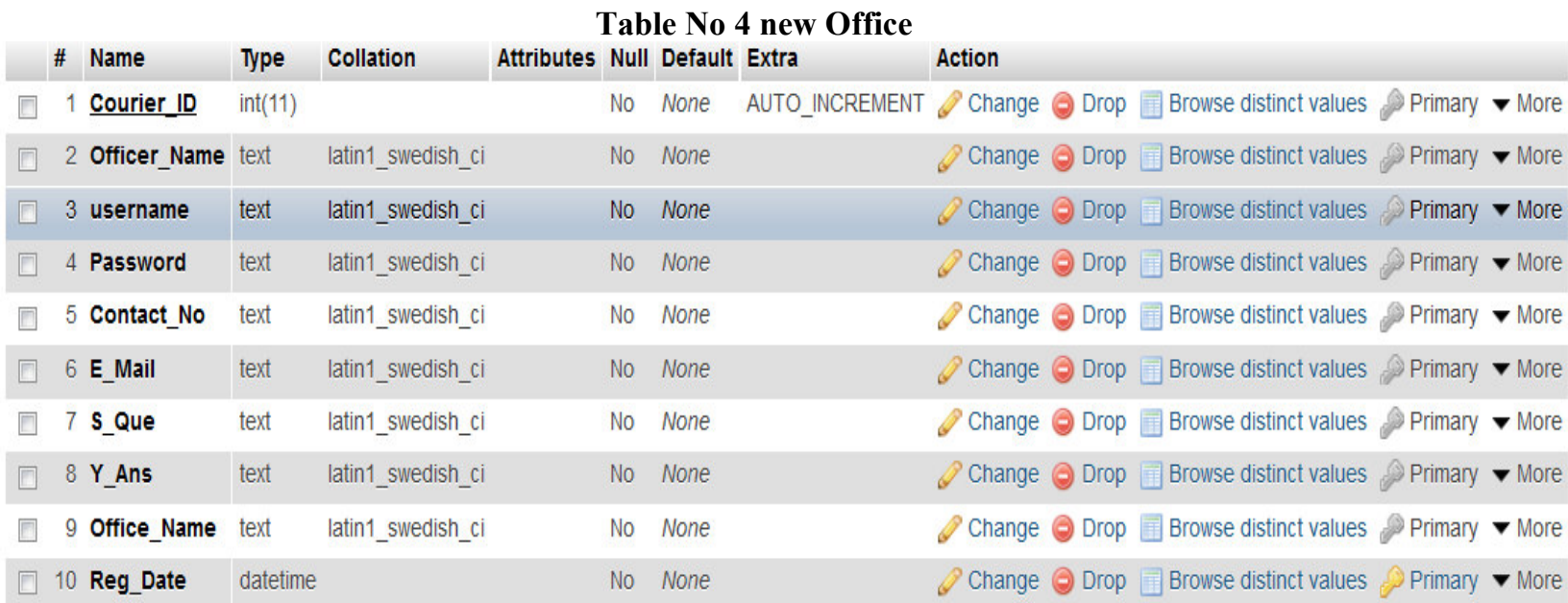

\section{Introduction to System Development}

The systems development life cycle (SDLC) is a conceptual model used in project management that describes the stages involved in an information system development project, from an initial feasibility study through maintenance of the completed application.

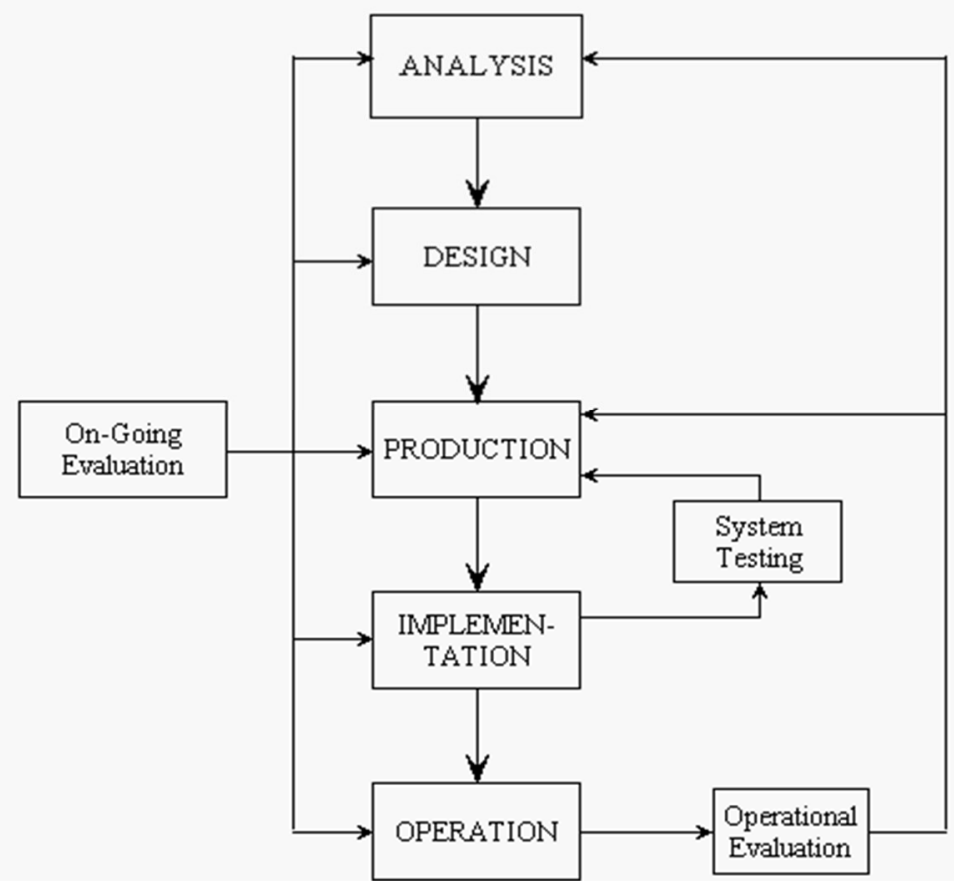

Fig 7. System development

\subsection{Tool/Language Selection}

Dreamweaver

MySQL

WINDOW 7

\subsection{Software Development \& Implementation}

In order to effectively implement a solution, it is necessary to understand the needs and expectations of the client and the problem. Intrafinity's five-phase Smart Work implementation methodology guides both our client and team through a proven process that ensures the best possible solution with defined expectations, budgets, and timeframes. The methodology's phases are Envisioning, Planning, Developing, Stabilizing, and Deploying. 


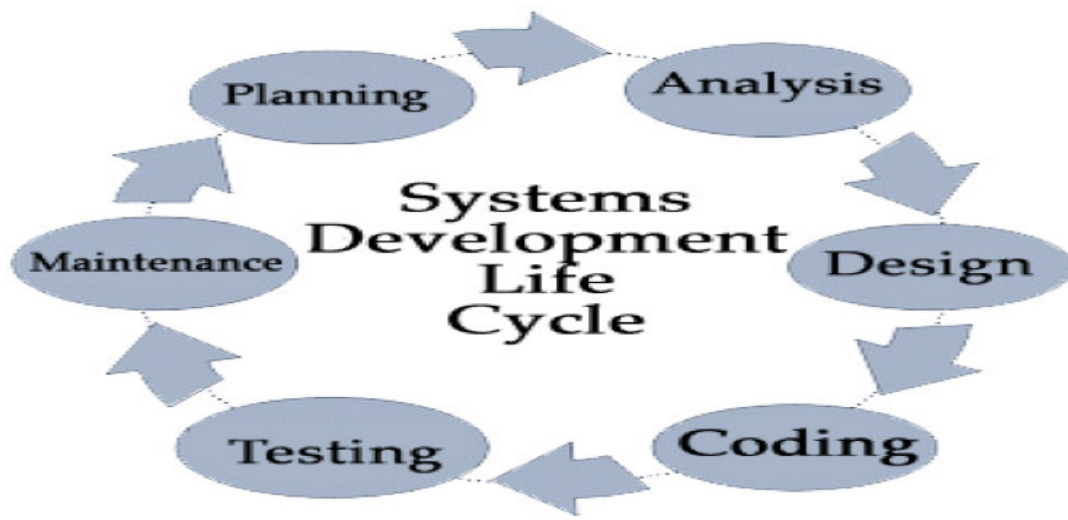

Fig 8.System development life cycle

\subsection{Admin login}

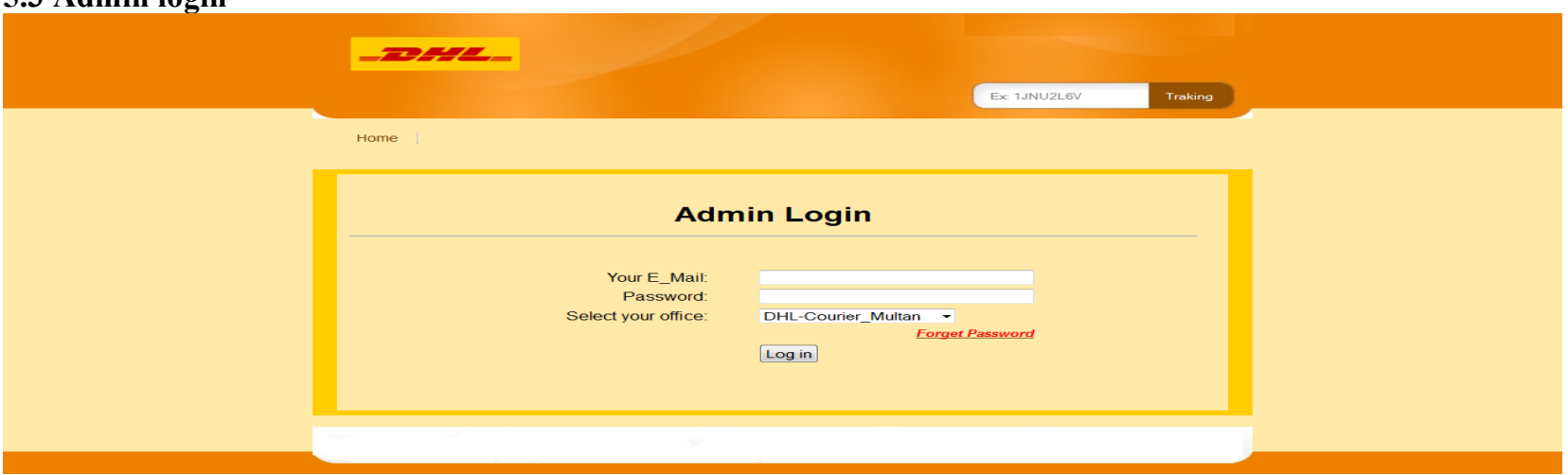

Figure 9. admin login with email, Password and office name.

\subsection{Record Link}

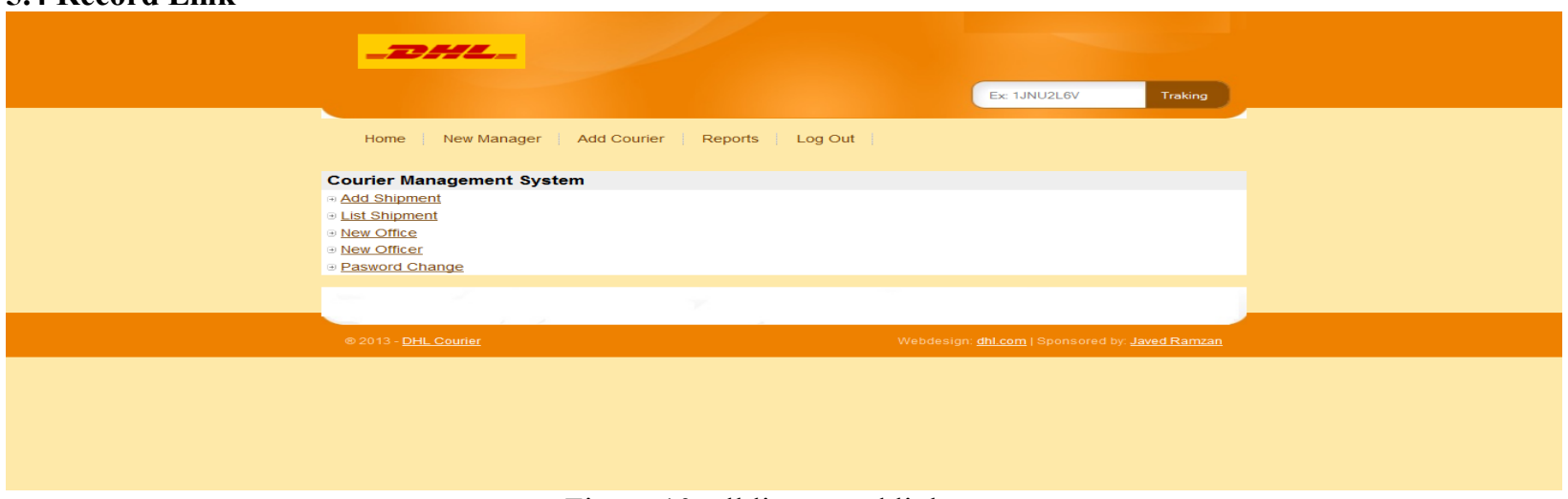

5.5 Add Shipment

Figure 10. all list record link.

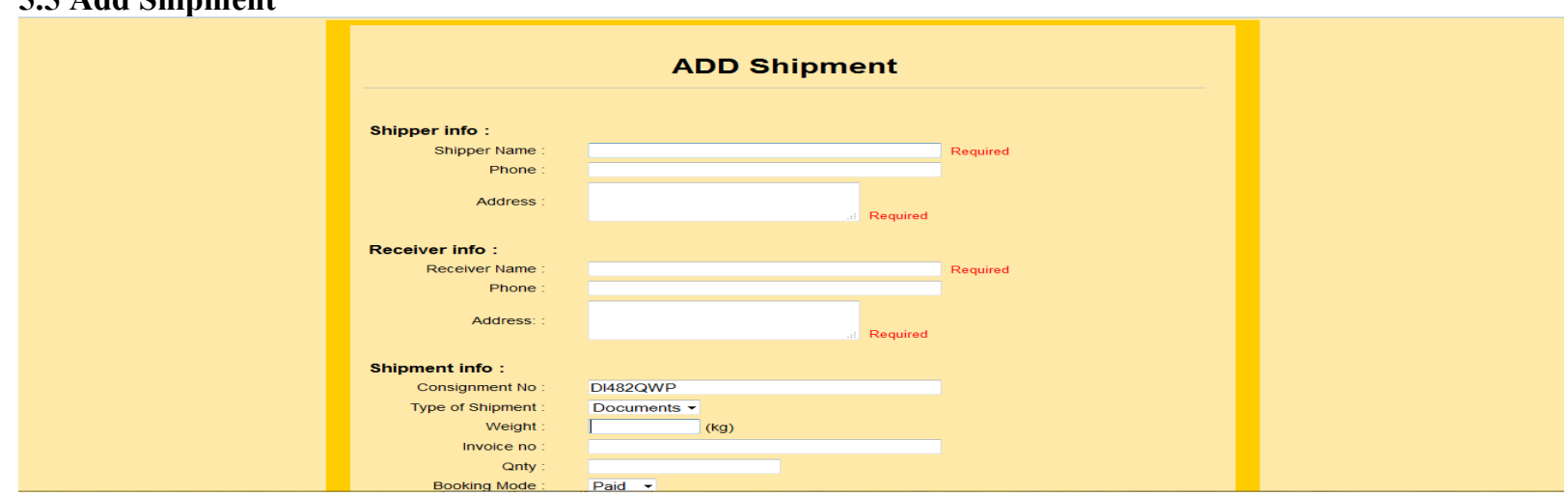

Figure 11. admin store new shipment record. 


\subsection{Deliverd Report}

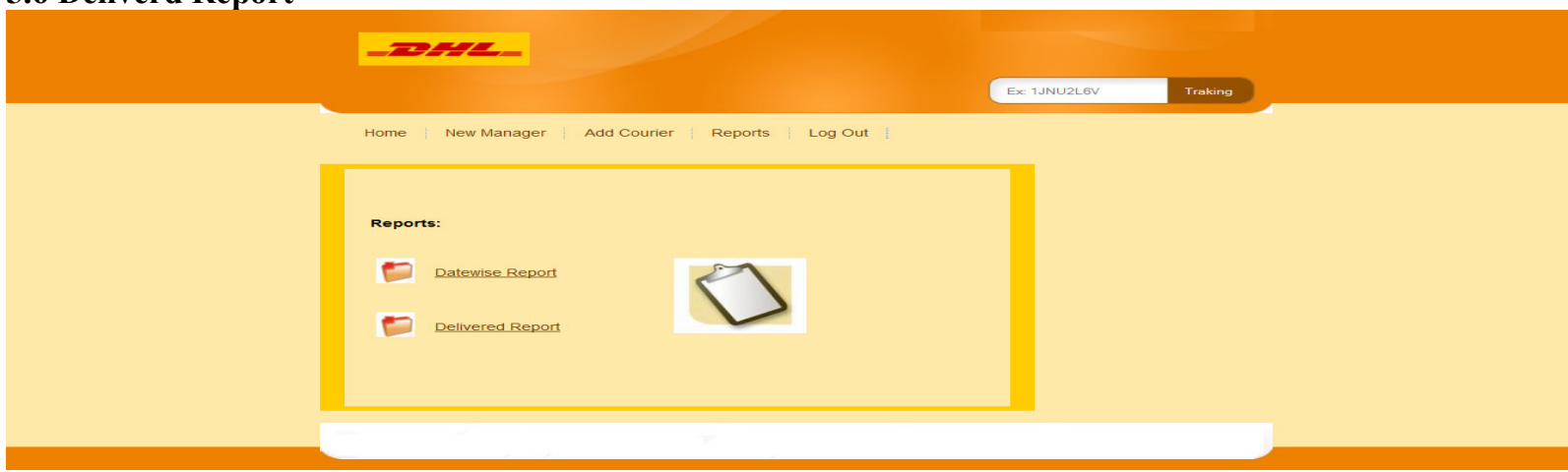

Figure 12. admin check datewise \& Deliverd report.

\subsection{Datewise Report}

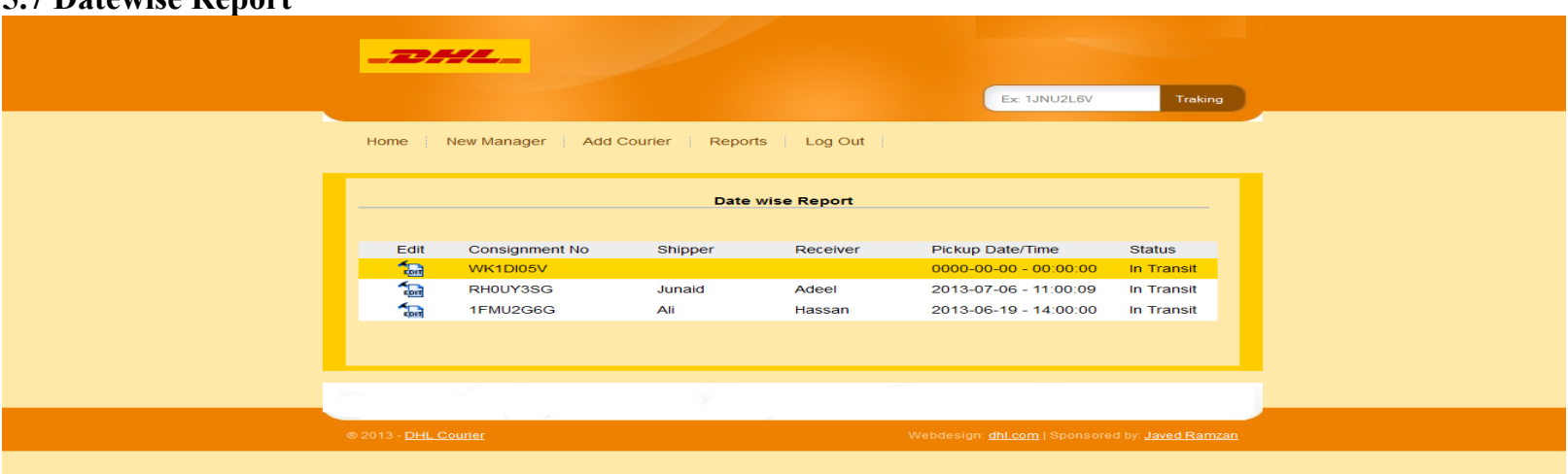

Figure 13. Datewise report

\subsection{Consignment Report}

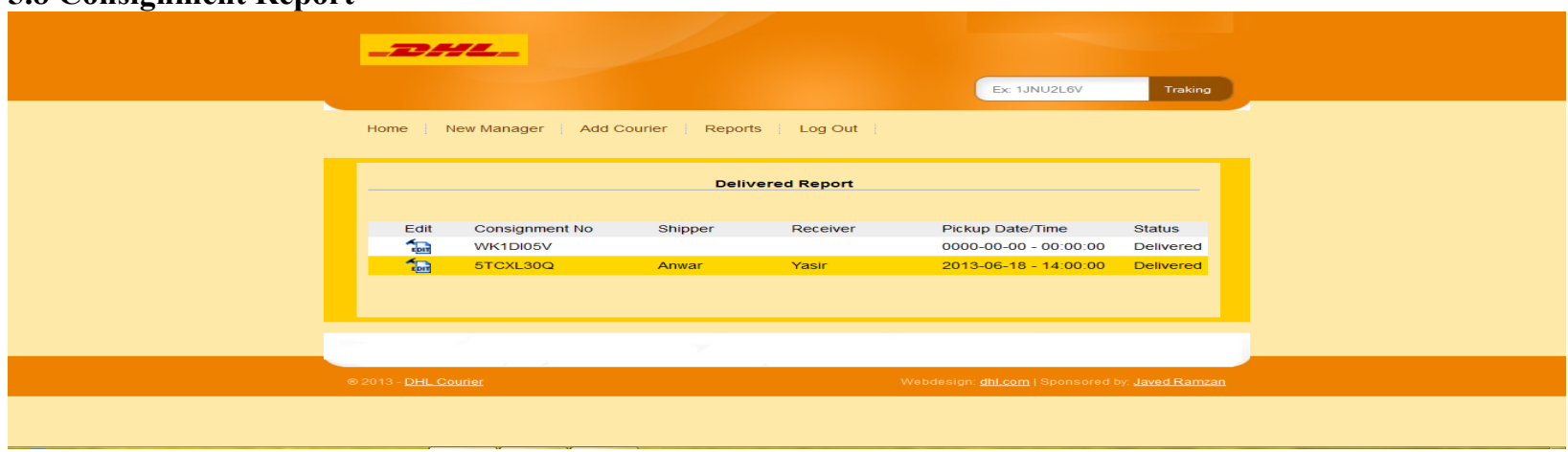

Figure 14. delivered consignment report.

\subsection{Tracking System}

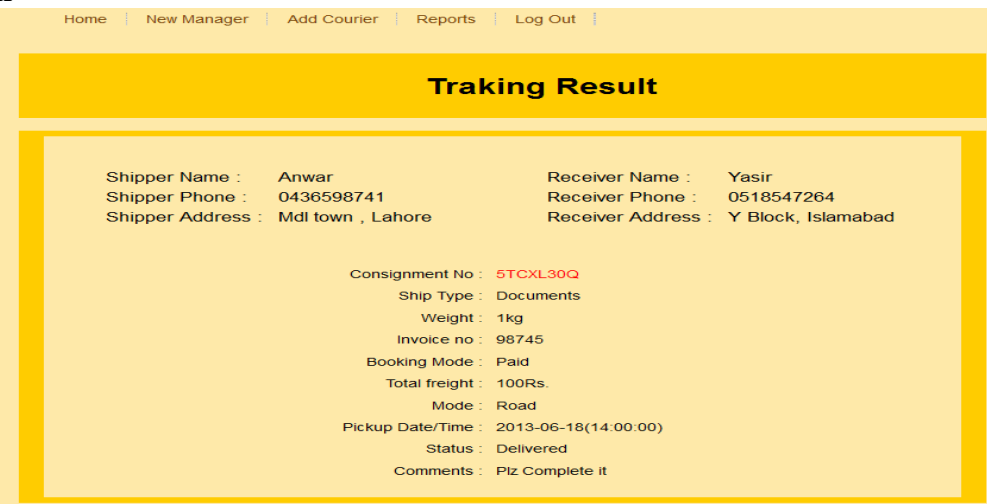

Figure 15. users search consignmet with tracking number. 


\subsection{Couriar List}

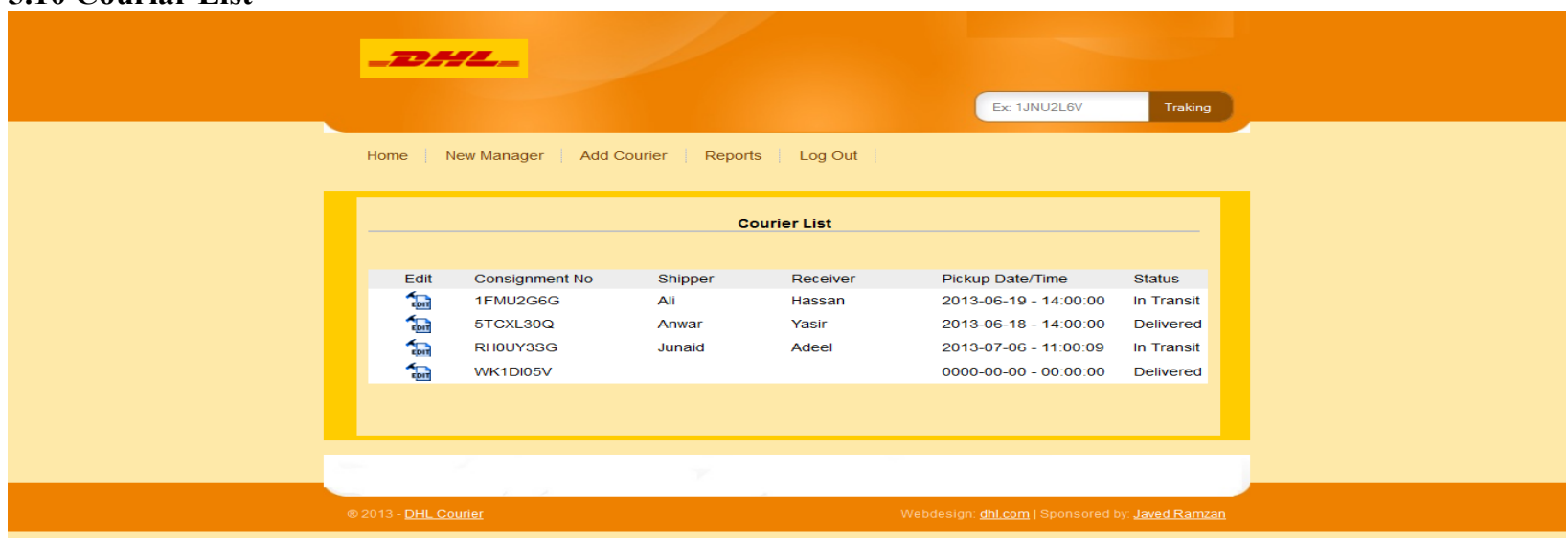

Figure 16. all consignment list which is stored in the DHL record.

\subsection{Add New Branch}

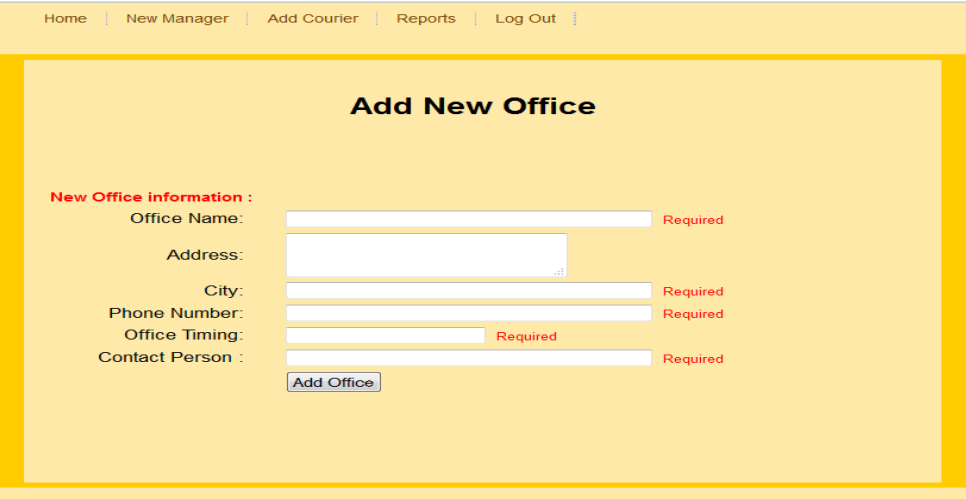

Figure17. admin add new branch.

\subsection{Change Password}

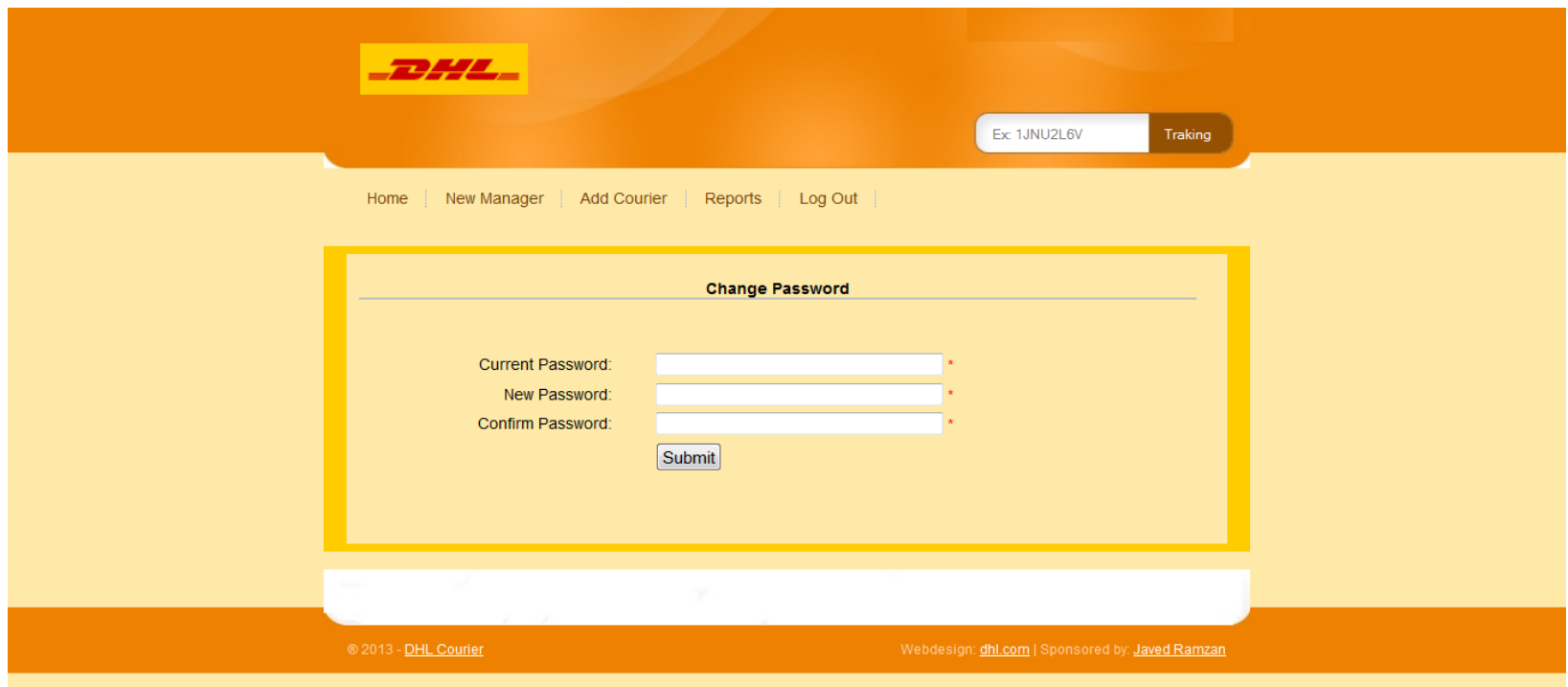

Figure 18. admin change or update current password. 


\subsection{Verification of Password}

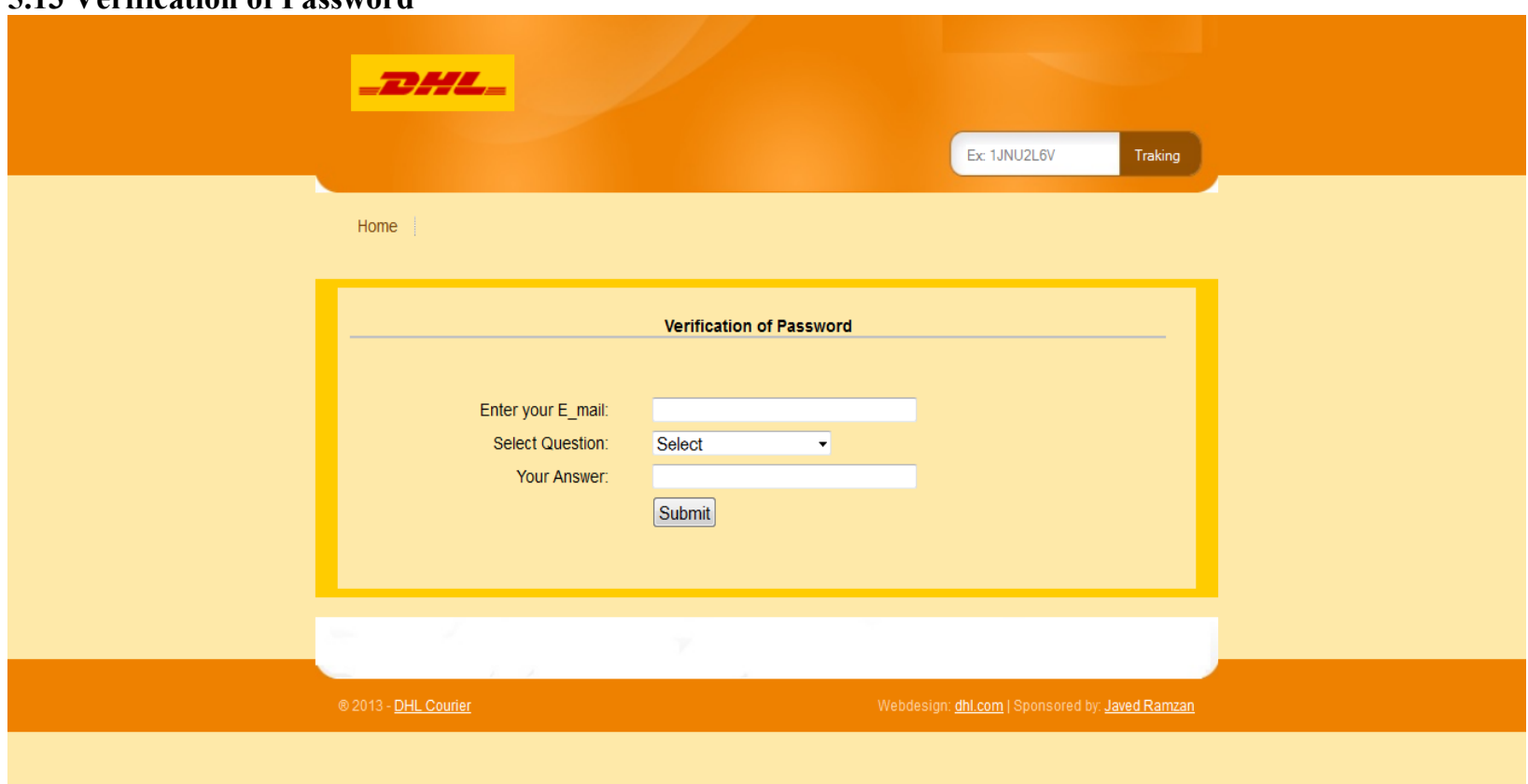

Figure 19. admin verify password if he forget current password.

\section{Conclusion}

This project is on DHL Courier System. This project provides facilities to admin as well as user. With the help of this software the admin can store data easily as compared to old manual system. In this project admin can search consignment current status with the help of consignment number and also update data. In this software admin can login to their profile and also retrieve or reset password. Customer can also get online information about their consignment with the help of tracking number and also about other DHL courier branches detail and their services. Using this software admin can update website. This software provide following facilities:

- Admin can see all consignment detail and can perform all type of operation on data.

- Admin have the access to all the employee profile and also can edit it.

- Customers can track consignment at home online by using this website.

- Customers can have the facility of online booking of their documents and other parcel.

\section{Reference}

[1] Azeta, A. A., Ogunlana A. O. and Ezeh C. O., (2010) Design and Implementation of a Mobile Express Delivery System, Proceedings of the International Conference on Software Engineering and Intelligent Systems, Ota, Nigeria SEIS 2010. Vol 1.

[2] Chauhan A., Singh S., Jain A. and Kumar R. (2010). High-Tech Courier Services as an E-Courier services in India Prospective. Report and Opinion 2010;2(5):86-93. ISSN:1553-9873.

[3] Chris. (2006). Courier System report.

[4] http://d1dlalugb0z2hd.cloudfront.net/highlight/pdfgenerator/courier.pdf

[5] Emeje, S (2013) Many courier companies are going down, interview with Punch newspaper August,19.

[6] Emeje, S (2014) Online Courier Business: Untapped Goldmine interview with Daily Newswatch September 15.

[7] Express Delivery Services (2005): Integrating ASEAN to Global Market. A report by US-ASEAN Business Council June 2005

[8] Fabiano R., (2010) Challenges and innovations in the courier and cargo industry, Supplement News, November 25 2010, 10:54 AM available on http://www.thejakartapost.com/news/2010/11/25/challenges-andinnovations-courier-and-cargo-industry.html\#sthash.XcNh8y77.dpuf 35

[9] Karlson A., Smith G. , Meyers B., Robertson G., and Czerwinski M., (2008), Courier: A Collaborative PhoneBased File Exchange System., Technical Report MSR-TR-2008-05, http://research.microsoft.com. [10] Murtagh R. (2014) Mobile Now Exceeds PC: The Biggest Shift Since the Internet Began, available at: $\mathrm{http}$ //searchenginewatch.com/sew/opinion/2353616/mobile-now-exceeds-pc-the-biggest-shift-since-theinternet-began Enhancing Courier Service with the Development... DOI: 10.9790/0050-0225661 www.iosrjournals.org $61 \mid$ Page

[11] Nigerian ICT Handbook (2003), a report of ICT product and services usage in Nigeria, published by 
Compumetrics Solutions Ltd, Lagos. http://compumetricsolutions.com.

[12] Orunga, E(2012), Challenges facing the Courier industry and their solutions available on http://www.dtrail.co.ke

[13] Yosep, Ricky M. (2014). Mobile Food Ordering Application using Android OS Platform. Paper presented at International Conference on Advances Science and Contemporary Engineering, Jarkata, Indonesia, volume 68.

[14] Isaac O (2010) Optimizing Opportunities for Courier Business In Nigeria, md/ceo, Red Star Express [15] Schmidt A. (2015), 'A Look at the Courier Service Industry in the United States' in What Investors Should Know about the Courier Services Industry (Part 1 of 11), available on http://www.marketrealist.com/2015/07/look-courier-service-industry-united-states/ 